\title{
Microglial activation in early Alzheimer trajectory is associated with higher gray matter volume
}

Grazia Daniela Femminella, MD, PhD, ${ }^{*}$ Melanie Dani, MD,* Melanie Wood, MD, Zhen Fan, MSc, Valeria Calsolaro, MD, Rebecca Atkinson, MSc, Trudi Edginton, PhD, Rainer Hinz, PhD, David J. Brooks, MD, FMedSci, and Paul Edison, MD, PhD, FRCP

Neurology ${ }^{\circledR}$ 2019;92:e1331-e1343. doi:10.1212/WNL.0000000000007133

\author{
Correspondence \\ Dr. Edison \\ paul.edison@imperial.ac.uk
}

\begin{abstract}
Objective

To investigate the influence of microglial activation in the early stages of Alzheimer's disease trajectory, we assessed the relationship between microglial activation and gray matter volume and hippocampal volume in patients with mild cognitive impairment (MCI).
\end{abstract}

\section{Methods}

In this study, 55 participants ( 37 with early stages of $\mathrm{MCI}$ and 18 controls) underwent $\left[{ }^{11} \mathrm{C}\right]$ PBR28 PET, a marker of microglial activation; volumetric MRI to evaluate gray matter and hippocampal volumes as well as clinical and neuropsychometric evaluation. $\left[{ }^{11} \mathrm{C}\right] \mathrm{PBR} 28 \mathrm{~V}_{\mathrm{T}}$ (volume of distribution) was calculated using arterial input function and Logan graphical analysis. Gray matter volume and hippocampal volumes were calculated from MRI for each participant. Statistical parametric mapping software was used to perform voxel-wise correlations and biological parametric mapping analysis. Amyloid status was assessed using $\left[{ }^{18} \mathrm{~F}\right]$ flutemetamol PET.

\section{Results}

Higher $\left[{ }^{11} \mathrm{C}\right] \mathrm{PBR} 28 \mathrm{~V}_{\mathrm{T}}$ in different cortical areas correlated with higher gray matter volume in both amyloid-positive and -negative MCI. In addition, higher hippocampal volume correlated with higher cortical $\left[{ }^{11} \mathrm{C}\right] \mathrm{PBR} 28$ Logan $\mathrm{V}_{\mathrm{T}}$.

\section{Conclusions}

In this in vivo study, we have demonstrated that microglial activation quantified using $\left[{ }^{11} \mathrm{C}\right]$ PBR28 PET was associated with higher gray matter volume and higher hippocampal volume in patients with MCI. This might suggest that microglial activation may not always be associated with neuronal damage, and indeed it may have a beneficial effect in the early stages of the Alzheimer trajectory. While further longitudinal studies are necessary, these findings have significant implications on therapeutic strategies targeting microglial activation. 


\section{Glossary}

AD = Alzheimer disease; $\mathbf{B P M}=$ biological parametric mapping; GWAS = genome-wide association studies; $\mathbf{H A B}=$ highaffinity binder; $\mathbf{H C}=$ healthy control; $\mathbf{M A B}=$ mixed-affinity binder; $\mathbf{M C I}=$ mild cognitive impairment; $\mathbf{M N I}=$ Montreal Neurological Institute; PBR = peripheral benzodiazepine receptor; $\mathbf{R O I}=$ region of interest; $\mathbf{S P M}=$ statistical parametric mapping; TSPO = 18-kDa translocator protein; $\mathbf{V B M}=$ voxel-based morphometry; $\mathbf{V}_{\mathrm{T}}=$ volume of distribution.

Amyloid plaque formation and tau aggregation are the hallmarks of Alzheimer disease $(\mathrm{AD})$ pathology. The failure of antiamyloid strategies in $\mathrm{AD}$ and mild cognitive impairment $(\mathrm{MCI})^{1}$ suggests that other mechanisms, such as neuroinflammation, may have a significant role in the neurodegenerative process. ${ }^{2,3}$ Microglia are responsible for maintaining the homeostasis and immune defense mechanism in brain, and become activated by any brain insults. Both $\beta$-amyloid and tau can trigger microglia activation, ${ }^{4-7}$ contributing to neuronal damage in established $\mathrm{AD}$. In prodromal $\mathrm{AD}$, microglial activation might have a protective role by clearing amyloid. ${ }^{2,8,9}$ Microglial activation is characterized by upregulation of the mitochondrial translocator protein, TSPO. ${ }^{10,11}$ Studies using the microglial marker $\left[{ }^{11} \mathrm{C}\right](\mathrm{R}) \mathrm{PK} 11195$-PET have demonstrated increased microglial activation in late $\mathrm{AD}$, which correlated inversely with memory performance. ${ }^{12}$ However, the role of microglial activation in the early stages of neurodegenerative diseases is still debated. Recently, we proposed that there could be 2 peaks of microglial activation in the $\mathrm{AD}$ trajectory, and indeed, the early peak could be protective while the later peak could be detrimental. $^{26}$

$\left[{ }^{11} \mathrm{C}\right]$ PBR28 is a TSPO ligand with 80 -fold-higher affinity ${ }^{13}$ than $\left[{ }^{11} \mathrm{C}\right] \mathrm{PK} 11195$, and minimal affinity for astrocytes. ${ }^{14}$ Gray matter volume measures the amount of gray matter within a region relative to other tissue types. ${ }^{15}$ It relates to the amount of atrophy, providing information on brain volume loss. ${ }^{15}$ In this study, we evaluated whether microglial activation in MCI assessed using $\left[{ }^{11} \mathrm{C}\right]$ PBR28 PET is associated with brain volume preservation, measured by gray matter and hippocampal volumes.

\section{Methods}

\section{Study population}

Fifty-five participants (37 patients with $\mathrm{MCI}$ and 18 healthy controls $[\mathrm{HCs}]$ ) were recruited from the Imperial College memory clinics, dementia registry, and memory clinics around London. Patients with MCI had a clinical diagnosis made by a specialist consultant at memory clinics, and the study investigators reviewed the patient according to the Petersen ${ }^{16}$ and National Institute on Aging-Alzheimer's Association criteria. ${ }^{17}$ Objective memory loss was measured by education-adjusted scores on the Wechsler Memory ScaleLogical Memory. The following were other inclusion criteria: (1) age range 50-85 years; (2) ability to give informed consent; and (3) at least 8 years of education. Exclusion criteria included the following: (1) depression; (2) any significant disease or unstable medical condition that could influence neuropsychological testing; (3) contraindications to MRI; (4) history of schizophrenia, schizoaffective disorder, bipolar disorder, or any history of electroconvulsive therapy; and (5) significant white matter microvascular disease on MRI scans. All participants had a detailed medical and neurologic workup and detailed neuropsychometric testing, which included the National Adult Reading Test, the Rey-Osterrieth Complex Figure, the Wechsler Memory Scale-Logical Memory, the Hopkins Verbal Learning Test-Revised, semantic and verbal fluency tests, Digit Span, Letter-Number Sequencing, and Trail Making A and B tests. All participants underwent genetic testing for the presence of Ala147Thr polymorphisms of their TSPO genes to establish their binding status for $\left[{ }^{11} \mathrm{C}\right] \mathrm{PBR} 28$ : they were stratified into high-affinity binders (HABs), mixedaffinity binders (MABs), or low-affinity binders. ${ }^{18}$ Because low-affinity binders show negligible binding, they were excluded from the study.

\section{Standard protocol approvals, registrations, and patient consents}

This study was approved by the local and regional research ethics committee (London Riverside Research Ethics Committee-National Health Research Services, Health Research Authority, UK), and approval for the administration of radioactivity was given by ARSAC (Administration of Radioactive Substances Advisory Committee).

\section{$\left[{ }^{11} \mathrm{C}\right]$ PBR28 PET, $\left[{ }^{18} \mathrm{~F}\right]$ flutemetamol PET, and MRI acquisition and analysis}

\section{[11 C]PBR28 PET}

All participants had $\left[{ }^{11} \mathrm{C}\right]$ PBR28 PET scans using a Siemens Biograph TruePoint PET/CT scanner (Siemens, Erlangen, Germany) at Imanova, London. $\left[{ }^{11} \mathrm{C}\right] \mathrm{PBR} 28$ was manufactured and supplied by Imanova, London. A low-dose CT scan was initially acquired for attenuation correction and to position the patient. A mean activity of $300.3( \pm 37) \mathrm{MBq}\left[{ }^{11} \mathrm{C}\right]$ PBR28 in $20 \mathrm{~mL}$ normal saline was injected IV over $20 \mathrm{sec}-$ onds. Three-dimensional dynamic data were acquired in list mode, and reconstruction was performed using standard Siemens software. Arterial whole blood activity was measured continuously with an online detector for the first 15 minutes while discrete blood samples were taken at $5,10,20,30,50$, 70 , and 90 minutes and centrifuged to detect whole blood and plasma radioactivity and to measure radioactive metabolite levels. $\left[{ }^{11} \mathrm{C}\right]$ PBR28 dynamic PET was corrected for head motion using the frame-by-frame realignment tool in statistical parametric mapping (SPM12, Wellcome Trust Centre 
for Neuroimaging) software. In this study, we have used Logan graphic analysis to generate the parametric maps for $\left[{ }^{11} \mathrm{C}\right]$ PBR28. ${ }^{19,20}$ The dynamic data of $\left[{ }^{11} \mathrm{C}\right]$ PBR28 tracer activity, plasma input function, and brain tissue were converted into a linear plot using graphic analysis by the MICK program, developed in MATLAB. Logan parametric maps of $\mathrm{V}_{\mathrm{T}}$ (volume of distribution) were then generated using MICK parametric mapping software.

\section{Creation of object map}

Using SPM12 and Analyze11, an individualized object map in PET space was created for each participant using the following steps: (1) the individual's MRI was coregistered to their native PET space; (2) gray matter, white matter, and CSF maps were generated by segmentation of the coregistered MRI, and a binarized gray matter mask was created using a threshold of 0.5 ; (3) a probabilistic region-of-interest (ROI) atlas ${ }^{21}$ in MNI (Montreal Neurological Institute) space was transformed into native PET space; and (4) the probabilistic atlas in PET space was then applied to the binarized individual gray matter mask to generate individualized gray matter ROIs. Regional Logan $V_{T}$ was estimated for frontal, temporal, parietal, and occipital cortical regions by sampling individual parametric maps. Additional ROIs in $\mathrm{AD}$, such as posterior cingulate, anterior cingulate, and medial temporal lobe, were also sampled.

\section{MRI scans}

MRI scans were acquired on a Verio, 3T clinical MRI system (Siemens, VB19) using a 32-channel head coil, and included a T1-weighted magnetization-prepared rapid-acquisition gradient echo sequence (repetition time $=2,400$ milliseconds $[\mathrm{ms}]$, echo time $=3.06 \mathrm{~ms}$, flip angle of 9 , inversion time $=900$ $\mathrm{ms}$, matrix $=256 \times 256)$ generating $1 \mathrm{~mm}^{3}$ isotropic voxels, for coregistration with the PET images for regional PET analysis. T2-weighted MRI sequences were also acquired to evaluate vascular and other structural abnormalities. The hippocampal volume was calculated using FreeSurfer (Harvard Medical School; surfer.nmr.mgh.harvard.edu).

\section{Gray matter volume}

Preprocessing was applied to generate a modulated normalized gray matter MRI map using voxel-based morphometry (VBM) for each participant. ${ }^{15,22}$ Initially, the raw MRIs were segmented into gray matter, white matter, and CSF. The gray matter was then normalized, and the gray matter-normalized parameters were further used in the spatial normalization of the raw whole brain image. Modulation was applied to correct for the global confounding effects during the spatial normalization, in order to account for the absolute volume of the gray matter (figure 1). ${ }^{15}$

\section{$\left[{ }^{18}\right.$ F]Flutemetamol PET}

$\left[{ }^{18} \mathrm{~F}\right]$ Flutemetamol was manufactured and supplied by GE Healthcare (Waukesha, WI) and PET scans were performed at the Imperial College Clinical Imaging Facility using a Siemens Biograph 6 PET/CT scanner. $\left[{ }^{18} \mathrm{~F}\right]$ Flutemetamol was injected IV as a single bolus over 20 seconds into an antecubital vein. Mean injected activity was $182.3( \pm 2.5) \mathrm{MBq}$. Fifty-two participants (17 HCs and 35 patients with $\mathrm{MCI}$ ) had $\left[{ }^{18} \mathrm{~F}\right]$ flutemetamol PET scans. Three participants were not available to complete the $\left[{ }^{18} \mathrm{~F}\right]$ flutemetamol PET scans

Figure 1 Biological parametric mapping correlation between $\left[{ }^{11} \mathrm{C}\right] \mathrm{PBR} 28$ volume of distribution and gray matter volume

A. $M C l A \beta+v e$



B. $\mathrm{MCl} \mathrm{A} \beta$-ve

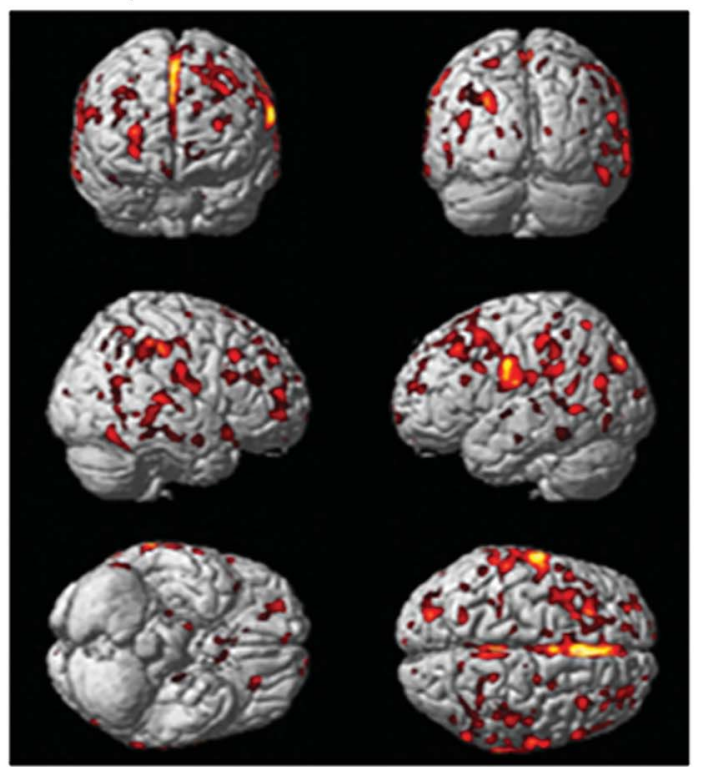

Correlation between higher $\left[{ }^{11} \mathrm{C}\right] \mathrm{PBR} 28$ and higher MRI gray matter density in $(\mathrm{A})$ amyloid-positive patients with MCI and (B) amyloid-negative patients with $\mathrm{MCl}$. $\mathrm{A} \beta=\beta$-amyloid; $\mathrm{MCl}=$ mild cognitive impairment. 
within the window allowed by the study protocol. The data were acquired 90 to 120 minutes post tracer injection using listmode in 3D. After creating an object map as described above, $\left[{ }^{18} \mathrm{~F}\right]$ flutemetamol uptake RATIO images in PET space was created using cerebellar gray matter as reference, and RATIO images were then sampled. To determine whether $\left[{ }^{18} \mathrm{~F}\right]$ flutemetamol uptake was abnormally increased in patients with $\mathrm{MCI}$ at the ROI level, we compared individual regional values to the control mean of the predefined regions. We considered a participant to be amyloid positive if the uptake ratio was $>2 \mathrm{SD}$ above the $\mathrm{HC}$ mean in at least one of our predefined cortical ROIs (frontal, temporal, parietal, and occipital cortices, anterior and posterior cingulate gyri). ${ }^{23}$

\section{Single-subject analysis}

Because a classic ROI approach for interrogating inhomogeneous microglial activation tends to underestimate the localized voxel-wise small changes within any predefined ROI region, we developed individualized SPM maps by comparing each patient against HCs to localize significant clusters of binding change. ${ }^{24,25}$ VOI (voxels of interest) maps for increased $\left[{ }^{11} \mathrm{C}\right] \mathrm{PBR} 28 \mathrm{~V}_{\mathrm{T}}$ for each participant were generated by extracting the significant clusters from the single-subject result in SPM12. The volume of each pathologic process was calculated using Analyze11, ${ }^{27}$ where each patient's $\left[{ }^{11} \mathrm{C}\right]$ PBR28 PET image was compared with their corresponding $\mathrm{HCs}$ for the $\mathrm{HAB}$ or MAB cohort. The statistical threshold for significance was set at $p<0.05$ and an extent threshold of 50 voxels.

\section{Correlation between $\left[{ }^{11} \mathrm{C}\right]$ PBR28 and hippocampal volume}

Initially, $\left[{ }^{11} \mathrm{C}\right] \mathrm{PBR} 28$ Logan parametric maps for individual participants were coregistered to the MRI, and then spatially transformed into MNI space. To evaluate the voxel-wise correlation between microglial activation and hippocampal volume, multiple regression was performed in SPM12 using Logan parametric maps of $\left[{ }^{11} \mathrm{C}\right] \mathrm{PBR} 28 \mathrm{~V}_{\mathrm{T}}$ as the dependent variable and hippocampal volumes calculated using FreeSurfer as the covariate of interest.

\section{Generation of $z$ score maps and biological parametric mapping correlation, and statistical analysis}

To compare the voxel-wise correlation between $\left[{ }^{11} \mathrm{C}\right] \mathrm{PBR} 28$ $\mathrm{V}_{\mathrm{T}}$ with the gray matter volume in patients with $\mathrm{MCI}, z$ score maps were generated for each participant for each modality. Smoothed and normalized individual Logan parametric maps of $\left[{ }^{11} \mathrm{C}\right]$ PBR28 $\mathrm{V}_{\mathrm{T}}$ were used for localizing microglial activation. The individual $z$ score maps for $\left[{ }^{11} \mathrm{C}\right] \mathrm{PBR} 28 \mathrm{~V}_{\mathrm{T}}$ and modulated gray matter map were created in SPM12 using the following formulae:

$$
\begin{aligned}
& Z([11 \mathrm{C}] \text { PBR28 })= \\
& \frac{\text { Patient }([11 \mathrm{C}] \mathrm{PBR} 28)-\dot{\mathrm{X}} \text { Control }([11 \mathrm{C}] \mathrm{PBR} 28)}{\text { SD of Control }([11 \mathrm{C}] \mathrm{PBR} 28)}
\end{aligned}
$$

$Z($ Grey matter MRI $)=$

$\frac{\text { Patient (Grey matter MRI) }-\dot{X} \text { Control (Grey matter MRI) }}{\text { SD of Control(Grey matter MRI) }}$

where $\mathrm{Z}$ denotes $z$ score map, $\dot{\mathrm{X}}$ denotes mean, and SD denotes standard deviation. Then individual $z$ score maps were applied in the biological parametric mapping (BPM) toolbox to assess the voxel-wise correlation, which uses the general linear model to perform regressions to provide a sophisticated comparison between different imaging modalities at a voxel level, as shown in figure $1 .{ }^{27}$ Individual $z$ score MRI maps provide the whole-brain profile of degree of gray matter volume. The $z$ score maps for $\mathrm{HAB}$ and $\mathrm{MAB}$ were created separately using corresponding controls. $\mathrm{HAB}$ and $\mathrm{MAB} z$ score maps were combined for the BPM analysis. Similarly, individual $z$ score maps were created for $\left[{ }^{18} \mathrm{~F}\right]$ flutemetamol, and BPM correlation between microglial activation and amyloid pathology was evaluated in amyloid-positive patients. ${ }^{28}$

Statistical analysis was performed using IBM SPSS 22 in Windows 7 (IBM Corp., Armonk, NY). Continuous variables were expressed as mean \pm SD. The Student $t$ test was used to compare normally distributed continuous variables between the 2 groups. Categorical variables were compared with the $\chi^{2}$ statistic. Significance was set at a threshold of $p<0.05$.

\section{Data availability}

These data may be shared with qualified scientific and medical researchers, upon researcher's request, as necessary for conducting research depending on the terms of our regulatory approvals and institutional policy.

\section{Results}

Patient demographics and neuropsychometric tests scores are presented in table 1 , while volumetric MRI measures are presented in table 2 .

Voxel-wise correlation between $\left[{ }^{11} \mathrm{C}\right] \mathrm{PBR} 28 \mathrm{~V}_{\mathrm{T}}$, hippocampal volume, and gray matter volume The voxel-wise BPM correlation analysis demonstrated correlation between higher $\left[{ }^{11} \mathrm{C}\right] \mathrm{PBR} 28$ Logan $\mathrm{V}_{\mathrm{T}}$ and higher MRI gray matter volume at a voxel threshold of $p<0.05$ with an extent threshold of 50 voxels. Separating the patients with MCI into amyloid-positive $(\mathrm{n}=19)$ and -negative $(\mathrm{n}=16)$ subgroups, the voxel-wise BPM correlations showed correlations between gray matter volume and $\left[{ }^{11} \mathrm{C}\right] \mathrm{PBR} 28 \mathrm{~V}_{\mathrm{T}}$ in both subgroups, mainly evident in frontal, temporal, and parietal regions in amyloid-positive patients with MCI (figure 2A, table 3 , and data available from Dryad, supplemental table 3, doi.org/10.5061/dryad.6mp3r21) and frontal and parietal regions in amyloid-negative patients (figure $2 \mathrm{~B}$, table 4 ). The BPM analysis between microglial activation and amyloid pathology in amyloid-positive patients with MCI showed areas of correlation in the posterior cingulate areas and middle frontal gyrus (data available from Dryad, supplemental table 4, doi.org/10.5061/dryad.6mp3r21). 
Table 1 Demographic characteristics and neuropsychometric test scores

\begin{tabular}{|c|c|c|c|c|}
\hline & Controls & $\mathrm{MCl}$ (all) & $\mathrm{A} \beta$-negative $\mathrm{MCl}$ & $A \beta$-positive $M C$ \\
\hline Total no. & 18 & 37 & 16 & 19 \\
\hline Mean age, y (SD) & $64.3(9.0)$ & $71.8(7.1)^{a}$ & $68.6(7.7)$ & $74.5(5.8)^{a, b}$ \\
\hline Age range, $y$ & $51-79$ & $56-84$ & $57-80$ & $56-84$ \\
\hline Sex, male & 7 & 20 & 10 & 8 \\
\hline MMSE score (SD) & $29.4(1.1)$ & $26.9(3.2)^{a}$ & $26.3(4.2)$ & $27.4(2.4)^{a}$ \\
\hline Education, y (SD) & $13.4(3.2)$ & $13.0(3.3)$ & $12.6(3.7)$ & $13.3(3.2)$ \\
\hline$A P O E \varepsilon 4$ carriers & $2 / 9$ & $12 / 23$ & $3 / 11$ & $7 / 10$ \\
\hline TSPO (HAB) & 11 & 22 & 10 & 11 \\
\hline \multicolumn{5}{|c|}{ Neuropsychometric test scores } \\
\hline NART errors & $12.6(7.7)$ & $15.4(11.9)$ & $17.7(11.4)$ & $13.8(12.6)$ \\
\hline IQ & $115.2(9.5)$ & $112.3(14.5)$ & $109.9(13.9)$ & $113.8(15.5)$ \\
\hline Rey copy & $34.3(2.5)$ & $30.4(6.0)^{a}$ & $29.8(5.5)^{a}$ & $30.9(6.6)$ \\
\hline Rey imm & $19.2(7.6)$ & $11.9(6.3)^{a}$ & $13.6(6.1)$ & $10.6(6.4)^{a}$ \\
\hline Rey del & $18.2(7.1)$ & $11.3(6.9)^{a}$ & $13.8(6.1)$ & $9.6(7.2)^{a}$ \\
\hline WLM imm & $44.5(8.6)$ & $26.8(10.4)^{a}$ & $27.7(9.6)^{a}$ & $26.3(11.4)^{\mathrm{a}}$ \\
\hline WLM del & $27.4(5.9)$ & $11.8(7.8)^{a}$ & $14.6(6.5)^{a}$ & $9.9(8.1)^{\mathrm{a}}$ \\
\hline Hopkins imm & $29.8(3.7)$ & $19.2(8.1)^{a}$ & $20.8(8.3)^{a}$ & $17.3(7.8)^{\mathrm{a}}$ \\
\hline Hopkins del & $10.2(2.1)$ & $5.1(3.9)^{\mathrm{a}}$ & $6.8(3.6)^{a}$ & $3.9(3.7)^{\mathrm{a}, \mathrm{b}}$ \\
\hline Hopkins RI & $11.3(1.1)$ & $8.0(3.6)^{a}$ & $8.4(3.2)^{a}$ & $7.5(3.9)^{a}$ \\
\hline Semantic fluency & $21.0(6.1)$ & $14.9(5.9)^{a}$ & $16.6(6.4)$ & $13.8(5.2)^{a}$ \\
\hline Verbal fluency & $49.4(10.8)$ & $36.3(14.7)^{a}$ & $36.0(14.2)^{a}$ & $36.1(15.9)^{a}$ \\
\hline Digit Span & $19.1(3.5)$ & $15.7(4.3)^{a}$ & $15.4(5.3)^{a}$ & $15.7(3.4)^{a}$ \\
\hline LNS & $11.1(3.1)$ & $6.8(4.2)^{a}$ & $6.9(4.7)^{\mathrm{a}}$ & $6.8(4.0)^{a}$ \\
\hline Trail Making A & $35.5(11.2)$ & $53.0(27.2)^{a}$ & $55.0(37.6)$ & $51.9(16.4)^{\mathrm{a}}$ \\
\hline Trail Making B & $71.5(21.4)$ & $143.9(75.1)^{a}$ & $123.7(61.3)^{a}$ & $158.8(84.8)^{a}$ \\
\hline
\end{tabular}

Abbreviations: $A \beta=\beta$-amyloid; del = delayed; $\mathrm{HAB}=$ high-affinity binder; imm = immediate; $L N S=$ Letter-Number Sequencing; $\mathrm{MCl}=$ mild cognitive impairment; MMSE = Mini-Mental State Examination; NART = National Adult Reading Test; RI = Recognition Index; TSPO = 18-kDa translocator protein; WLM = Wechsler Memory Scale-Logical Memory.

a $p<0.05$ vs controls ( $t$ test).

${ }^{\text {b }} p<0.05$ vs $A \beta$ negative $(t$ test).

The mean total hippocampal volume was lower in patients with MCI (left 3,512.9 $\pm 561 \mathrm{~mm}^{3}$; right 3,363.2 $\pm 591 \mathrm{~mm}^{3}$ ) $(p<0.05)$ compared to the HCs (left 4,052.4 $\pm 389 \mathrm{~mm}^{3}$; right $\left.3,808.9 \pm 462 \mathrm{~mm}^{3}\right)$. The multiple regression analysis in SPM revealed a correlation between higher $\left[{ }^{11} \mathrm{C}\right] \mathrm{PBR} 28 \mathrm{~V}_{\mathrm{T}}$ and total higher hippocampal volume in the MCI cohort using binding status (high or mixed affinity) as a covariate. Evaluating the participants separately depending on their TSPO binding status, in the MCI cohort with HABs for TSPO, higher hippocampal volume correlated with higher $\left[{ }^{11} \mathrm{C}\right] \mathrm{PBR} 28 \mathrm{~V}_{\mathrm{T}}$ in frontal, temporal, parietal, and occipital lobes (voxel threshold of $p<5 \mathrm{e}-11$ and extent threshold of 200 voxels) (figure 3A, table 5). In the MCI cohort with MABs for TSPO, higher hippocampal volume was correlated with higher $\left[{ }^{11} \mathrm{C}\right] \mathrm{PBR} 28$ $\mathrm{V}_{\mathrm{T}}$ in temporal and occipital lobes (voxel threshold of $p<5 \mathrm{e}-7$, and extent threshold of 200 voxels) (figure 3B, table 5). Regional $\left[{ }^{11} \mathrm{C}\right] \mathrm{PBR} 28 \mathrm{~V}_{\mathrm{T}}$ in controls and patients with $\mathrm{MCI}$ are given in data available from Dryad (supplemental table 1, doi.org/10. $5061 /$ dryad.6mp3r21), and regional $\left[{ }^{18} \mathrm{~F}\right]$ flutemetamol targetto-cerebellum ratios are presented in data available from Dryad (supplemental table 2, doi.org/10.5061/dryad.6mp3r21). Individually, 13 of 37 patients with MCI (35\%) were classified as having increased $\left[{ }^{11} \mathrm{C}\right] \mathrm{PBR} 28 \mathrm{~V}_{\mathrm{T}}$ compared to controls on single-subject SPM analysis. At the ROI level, there was no correlation between higher $\left[{ }^{11} \mathrm{C}\right] \mathrm{PBR} 28 \mathrm{~V}_{\mathrm{T}}$ and higher gray matter or hippocampal volume. 
Table 2 Volumetric measures in control participants and patients with $\mathrm{MCl}\left(\mathrm{mm}^{3}\right)$

\begin{tabular}{lllll}
\hline & Controls & MCI (all) & A -negative MCI & A -positive MCI \\
\hline Left hippocampus & $4,052.4 \pm 389$ & $3,512.9 \pm 561^{\mathrm{a}}$ & $3,754.3 \pm 386.7$ & $3,353.3 \pm 608.4^{\mathrm{a}, \mathrm{b}}$ \\
\hline Right hippocampus & $3,808.9 \pm 462$ & $3,363.2 \pm 591^{\mathrm{a}}$ & $3,624.8 \pm 361.9$ & $3,173.3 \pm 673.3^{\mathrm{a}, \mathrm{b}}$ \\
\hline Left amygdala & $1,545.2 \pm 171.1$ & $1,386.7 \pm 273.2$ & $1,523.4 \pm 246.7$ & $1,302.6 \pm 249.3^{\mathrm{a}, \mathrm{b}}$ \\
\hline Right amygdala & $1,650.1 \pm 216.3$ & $1,393.1 \pm 297.1^{\mathrm{a}}$ & $1,546.9 \pm 182.6$ & $1,261.5 \pm 315.8^{\mathrm{a}, \mathrm{b}}$ \\
\hline Left hemisphere cortex & $222,957.8 \pm 23,020.4$ & $216,283.3 \pm 22,989.2$ & $223,368.7 \pm 22,707.9$ & $209,825.4 \pm 22,639.0$ \\
\hline Right hemisphere cortex & $222,561.3 \pm 23,320.5$ & $213,707.6 \pm 23,290.0$ & $223,360.6 \pm 22,214.8$ & $204,789.6 \pm 21,765.0^{\mathrm{a}, \mathrm{b}}$ \\
\hline Total gray matter volume & $611,207.6 \pm 53,670.6$ & $589,724.3 \pm 56,167.5$ & $610,749.7 \pm 58,440.1$ & $569,668.1 \pm 49,783.4^{\mathrm{a}, \mathrm{b}}$ \\
\hline Left lateral ventricle & $10,539.9 \pm 4,916.2$ & $17,016.7 \pm 9,973.6^{\mathrm{a}}$ & $18,785.9 \pm 12,962.4^{\mathrm{a}}$ & $14,397.4 \pm 5,949.0^{\mathrm{a}}$ \\
\hline Right lateral ventricle & $10,862.3 \pm 5,097.7$ & $18,100.0 \pm 9,213.7^{\mathrm{a}}$ & $20,061.9 \pm 11,932.9^{\mathrm{a}}$ & $15,579.4 \pm 5,758.1^{\mathrm{a}}$ \\
\hline Third ventricle & $1,288.1 \pm 483.4$ & $1,646.3 \pm 612.0$ & $1,734.0 \pm 733.8^{\mathrm{a}}$ & $1,548.4 \pm 522.2$ \\
\hline Fourth ventricle & $1,759.8 \pm 446.2$ & $2,003.0 \pm 664.4$ & $2,188.37 \pm 879.1$ & $1,812.8 \pm 395.8$ \\
\hline
\end{tabular}

Abbreviations: $A \beta=\beta$-amyloid; $\mathrm{MCl}=$ mild cognitive impairment.

${ }^{a} p<0.05$ vs controls ( $t$ test)

${ }^{\mathrm{b}} p<0.05$ vs $A \beta$ negative ( $t$ test).

\section{Discussion}

In this study, we have demonstrated that $\left[{ }^{11} \mathrm{C}\right] \mathrm{PBR} 28$ Logan $\mathrm{V}_{\mathrm{T}}$ in different cortical areas is associated with higher hippocampal volume and greater gray matter volume in the early stages of the $\mathrm{AD}$ trajectory. This may suggest that microglia, which maintains the natural homeostatic/defense mechanism of the brain, initially responds by trying to protect the brain. Recent studies have demonstrated that $\left[{ }^{11} \mathrm{C}\right] \mathrm{PBR} 28$ is specific for activated microglia, ${ }^{14,29}$ and this study highlights the role of microglia in protecting the brain in the very early stages of neurodegeneration. This is in contrast to the role of microglia in established $\mathrm{AD}$, where microglial activation exerts a deleterious effect.

Because microglial cells are the primary immune effector cells in the brain, in response to any kind of brain damage, they become activated and undergo morphologic and functional

Figure 2 Biological parametric mapping correlation between $\left[{ }^{11} \mathrm{C}\right] \mathrm{PBR} 28 \mathrm{~V}_{\mathrm{T}}$ and hippocampal volume
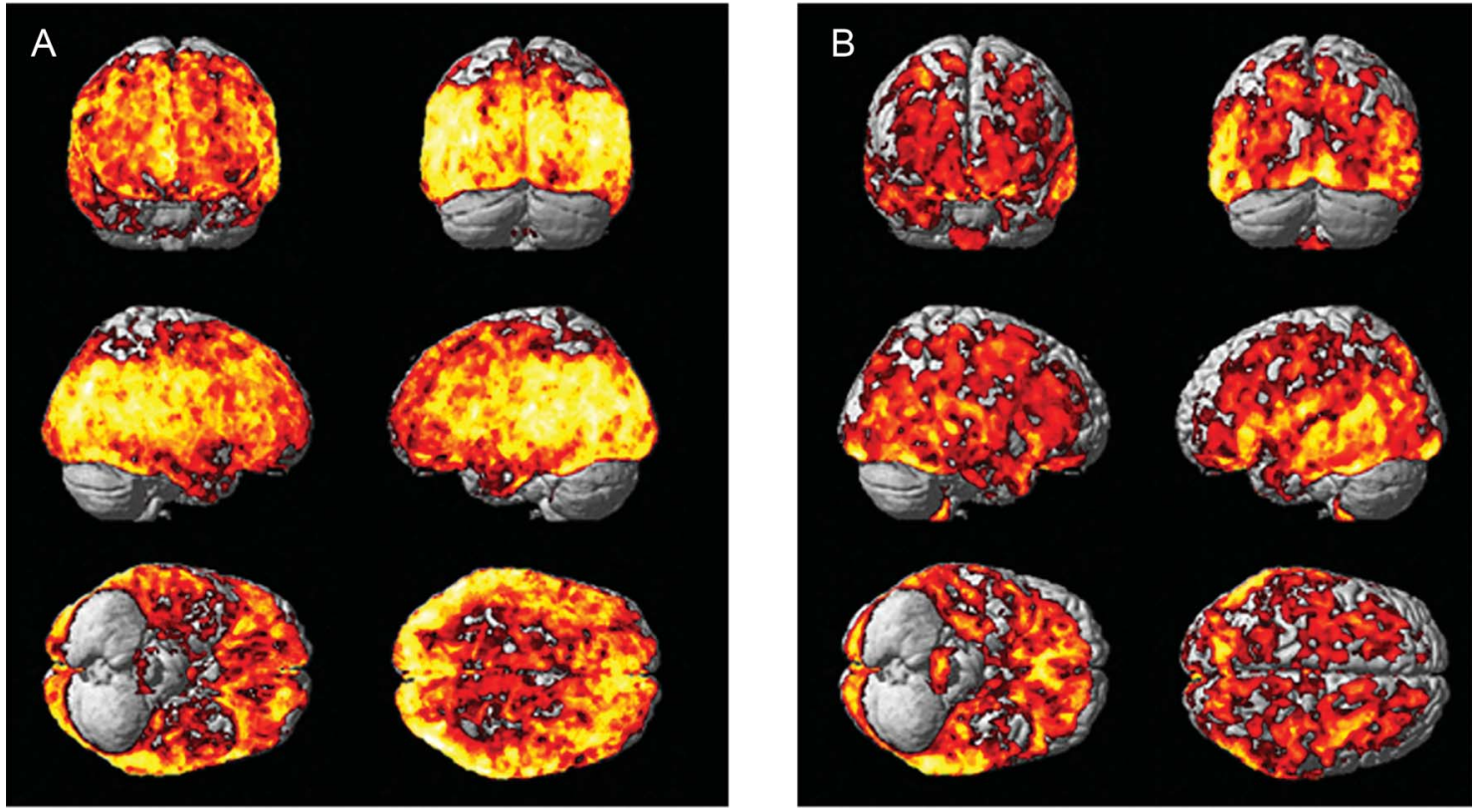

Correlation between higher microglial activation $\left(\left[{ }^{11} \mathrm{C}\right] \mathrm{PBR} 28 \mathrm{~V}_{\mathrm{T}}\right)$ and hippocampal volume in patients with $\mathrm{HAB}(\mathrm{A})$ and $\mathrm{MAB}(\mathrm{B}) \mathrm{status}$ and mild cognitive impairment. $\mathrm{V}_{\mathrm{T}}=$ volume of distribution. 
Table 3 Clusters of voxel-wise correlation between higher $\left[{ }^{11} \mathrm{C}\right] P B R 28 \mathrm{~V}_{\mathrm{T}}$ and gray matter volume in amyloid-positive patients with $\mathrm{MCl}$ using biological parametric mapping

\begin{tabular}{|c|c|c|c|c|c|c|}
\hline \multirow[b]{2}{*}{ Region } & \multirow[b]{2}{*}{ Size } & \multicolumn{3}{|c|}{ MNI coordinates } & \multirow[b]{2}{*}{ z Score } & \multirow[b]{2}{*}{ Corrected $p$ value } \\
\hline & & $x$ & $\mathbf{Y}$ & z & & \\
\hline Left insula & 19,344 & -24 & -28 & -2 & 4.65 & $<0.0001$ \\
\hline Left inferolateral parietal lobe & & -23 & -28 & 21 & 4.2 & \\
\hline Left thalamus & & -19 & -25 & 15 & 4.06 & \\
\hline Right thalamus & & 1 & -12 & 0 & 3.8 & \\
\hline Left postcentral gyrus & & -24 & -25 & 43 & 3.95 & \\
\hline Left posterior temporal lobe & & -47 & -34 & 4 & 3.61 & \\
\hline Left superior temporal gyrus & & -41 & -29 & -6 & 3.45 & \\
\hline Left parahippocampal and ambient gyri & & -29 & -30 & -15 & 3.03 & \\
\hline Left inferolateral of parietal lobe & & -33 & -33 & 25 & 3.72 & \\
\hline Left caudate nucleus & & -9 & 15 & 11 & 2.72 & \\
\hline Left fusiform gyrus & & -39 & -31 & -25 & 2.68 & \\
\hline Right insula & & 35 & 10 & -17 & 4.61 & 0.001 \\
\hline Right anterior temporal lobe & 4,640 & 33 & 7 & -20 & 4.01 & \\
\hline Right superior temporal gyrus & & 39 & 16 & -22 & 3.08 & \\
\hline Right hippocampus & & 16 & -9 & -21 & 2.59 & \\
\hline Right parahippocampal and ambient gyri & & 14 & -10 & -26 & 2.48 & \\
\hline Right amygdala & & 15 & -5 & -17 & 2.02 & \\
\hline Right postcentral gyrus & & 35 & -36 & 65 & 3.16 & 0.001 \\
\hline Right precentral gyrus & & 32 & -18 & 62 & 2.48 & \\
\hline Right superior parietal gyrus & 4,306 & 27 & -42 & 62 & 2.3 & \\
\hline Left lateral occipital lobe & & -19 & -93 & 10 & 3 & 0.006 \\
\hline Left cuneus & & -5 & -82 & 19 & 2.91 & \\
\hline Right cuneus & 3,608 & 5 & -83 & 16 & 1.86 & \\
\hline
\end{tabular}

transformations, along with structural changes. Microglia express (1) AMPA ( $\alpha$-amino-3-hydroxy-5-methyl-4-isoxazole propionic acid) receptors to respond to glutamate, (2) P2 purinoceptors to respond to ATP (adenosine 5'-triphosphate) and other nucleotides, (3) cytokine receptors to respond to tumor necrosis factor $\alpha$ and interleukin $1 \beta$, and (4) receptors for the major histocompatibility complex class antigens and chemokines. Activation of these receptors induces signaling cascades that are involved in microglia chemotaxis, activation, and phagocytosis, and protecting the brain from injury. ${ }^{2}$ It is suggested that amyloid aggregation can induce microglial activation, which may have a protective effect by promoting oligomer and fibril clearance in the early phases of the disease. ${ }^{30}$ One could argue the preservation of the brain volume associated with increased microglial activation seen in this study is consistent with the natural defense mechanism of the microglial response to neuronal injury; indeed, the participants included in this study have predominantly early $\mathrm{MCI}$, in which their impairment in cognitive function is minimal.

In our cohort, $55 \%$ of all participants with $\mathrm{MCI}$ had a positive amyloid scan, and therefore, according to the recently revised research criteria for a biological definition of $\mathrm{AD}$, fall within the trajectory of the $\mathrm{AD}$ continuum. ${ }^{31}$ Although their " $\mathrm{T}$ " (aggregated tau) status is unknown, they are "A" (amyloid) positive and " $\mathrm{N}$ " (neurodegeneration) positive as a group, based on the ATN classification. The other $45 \%$ of patients with MCI have a negative amyloid scan; therefore, they can be classified as "non-AD pathologic change" or "suspected non-AD pathophysiology." This latter group might include participants with primary age-related tauopathy, hippocampal sclerosis, TDP-43 (TAR DNA-binding protein 43) pathology, primary progressive aphasia, or cerebrovascular disease. ${ }^{32}$ In both amyloid- and nonamyloiddriven neurodegeneration, microglial activation could have an important role in modulating propagation of proteinopathies. 
Table 4 Clusters of voxel-wise correlation between higher $\left[{ }^{11} \mathrm{C}\right]$ PBR28 $\mathrm{V}_{\mathrm{T}}$ and gray matter volume in amyloid-negative patients with $\mathrm{MCl}$ using biological parametric mapping

\begin{tabular}{|c|c|c|c|c|c|c|}
\hline \multirow[b]{2}{*}{ Region } & \multirow[b]{2}{*}{ Size } & \multicolumn{3}{|c|}{ MNI coordinates } & \multirow[b]{2}{*}{$z$ Score } & \multirow[b]{2}{*}{ Corrected $p$ value } \\
\hline & & $\mathbf{x}$ & $\mathbf{Y}$ & $\mathbf{z}$ & & \\
\hline Left postcentral gyrus & & -65 & -10 & 25 & 4.76 & $<0.0001$ \\
\hline Left precentral gyrus & & -28 & -7 & 36 & 3.64 & \\
\hline Left middle frontal gyrus & 11,103 & -28 & 25 & 42 & 3.46 & \\
\hline Left inferolateral parietal lobe & & -66 & -23 & 19 & 2.63 & \\
\hline Left superior frontal gyrus & & -23 & 17 & 59 & 2.3 & \\
\hline Right middle frontal gyrus & & 31 & 19 & 32 & 3.77 & $<0.0001$ \\
\hline Right inferolateral parietal lobe & & 30 & -22 & 31 & 3.49 & \\
\hline Right precentral gyrus & 9,608 & 17 & -10 & 38 & 3.31 & \\
\hline Right postcentral gyrus & & 30 & -15 & 27 & 2.95 & \\
\hline Right insula & & 29 & -28 & 8 & 2.87 & \\
\hline Right posterior temporal lobe & & 35 & -34 & 9 & 2.83 & \\
\hline Right superior parietal gyrus & & 30 & -25 & 34 & 2.7 & \\
\hline Right middle frontal gyrus & & 19 & 40 & -1 & 3.42 & 0.007 \\
\hline Right subgenual frontal cortex & & 13 & 30 & -7 & 2.44 & \\
\hline Right cingulate gyrus & 3,694 & 9 & 34 & 8 & 2.32 & \\
\hline Right superior frontal gyrus & & 20 & 34 & 17 & 2.21 & \\
\hline Left superior frontal gyrus & & -1 & 20 & 64 & 3.28 & 0.001 \\
\hline Right gyrus cinguli & & 1 & -5 & 46 & 3.25 & \\
\hline Right superior frontal gyrus & 11,850 & 2 & 29 & 43 & 3.06 & \\
\hline Left cingulate gyrus & & -9 & 32 & 17 & 2.84 & \\
\hline Right precentral gyrus & & 13 & -18 & 57 & 2.5 & \\
\hline
\end{tabular}

Abbreviations: $\mathrm{MNI}=$ Montreal Neurological Institute; $\mathrm{V}_{\mathrm{T}}=$ volume of distribution.

It is possible that, as the disease advances, microglia become dysmorphic and dysfunctional, resulting in amyloid accumulation due to failure of clearance and the secretion of proinflammatory cytokines, promoting neurodegeneration. While it is possible to have a protective role for microglia in early stages of the disease, microglial activation in established $\mathrm{AD}$ is likely to have a deleterious effect. It has been shown that higher cortical microglial activation correlated with lower Mini-Mental State Examination scores and regional cerebral glucose metabolic rates in established $\mathrm{AD},{ }^{33}$ supporting the view that microglial activation drives neuronal dysfunction in later stages of the disease as in established $\mathrm{AD}$ with significant cognitive dysfunction. ${ }^{12,26,34} \mathrm{It}$ has also been shown that levels of microglial activation increase with disease progression in established $\mathrm{AD} .^{12,33}$ Recently, it has been demonstrated that brain inflammation is associated with amyloid deposition in the majority of $\mathrm{MCI}$ cases due to $\mathrm{AD} .^{35}$

There are 2 different types of activation pattern of microglial cells, allowing the classification of the cells into 2 different phenotypes: proinflammatory (M1), or classically activated; and the protective (M2) phenotype, which is alternatively activated. The switch from the anti-inflammatory to proinflammatory state is a dynamic process with a significant influence from peripheral inflammation. ${ }^{36}$ Jimenez et al. ${ }^{37}$ demonstrated a distinctive shift from anti-inflammatory to proinflammatory phenotype of microglial activation in the hippocampus of aged rodents. ${ }^{38}$ As depicted in the data available from Dryad (supplemental figure 1A, doi.org/10. $5061 /$ dryad.6mp3r21), one could argue that in the early stages, the protective phenotype of the microglia is activated. While TSPO tracers are unable to differentiate between the anti-inflammatory and proinflammatory phenotype, positive correlation between the microglial activation and gray matter volume suggests that the influence of early microglial activation may be beneficial, even though longitudinal studies are necessary to confirm this. Of note, recent studies suggest astrocyte activation also occurs in the early stages of $\mathrm{AD}$ pathology. ${ }^{39,40}$ One could argue that both astrocyte and 


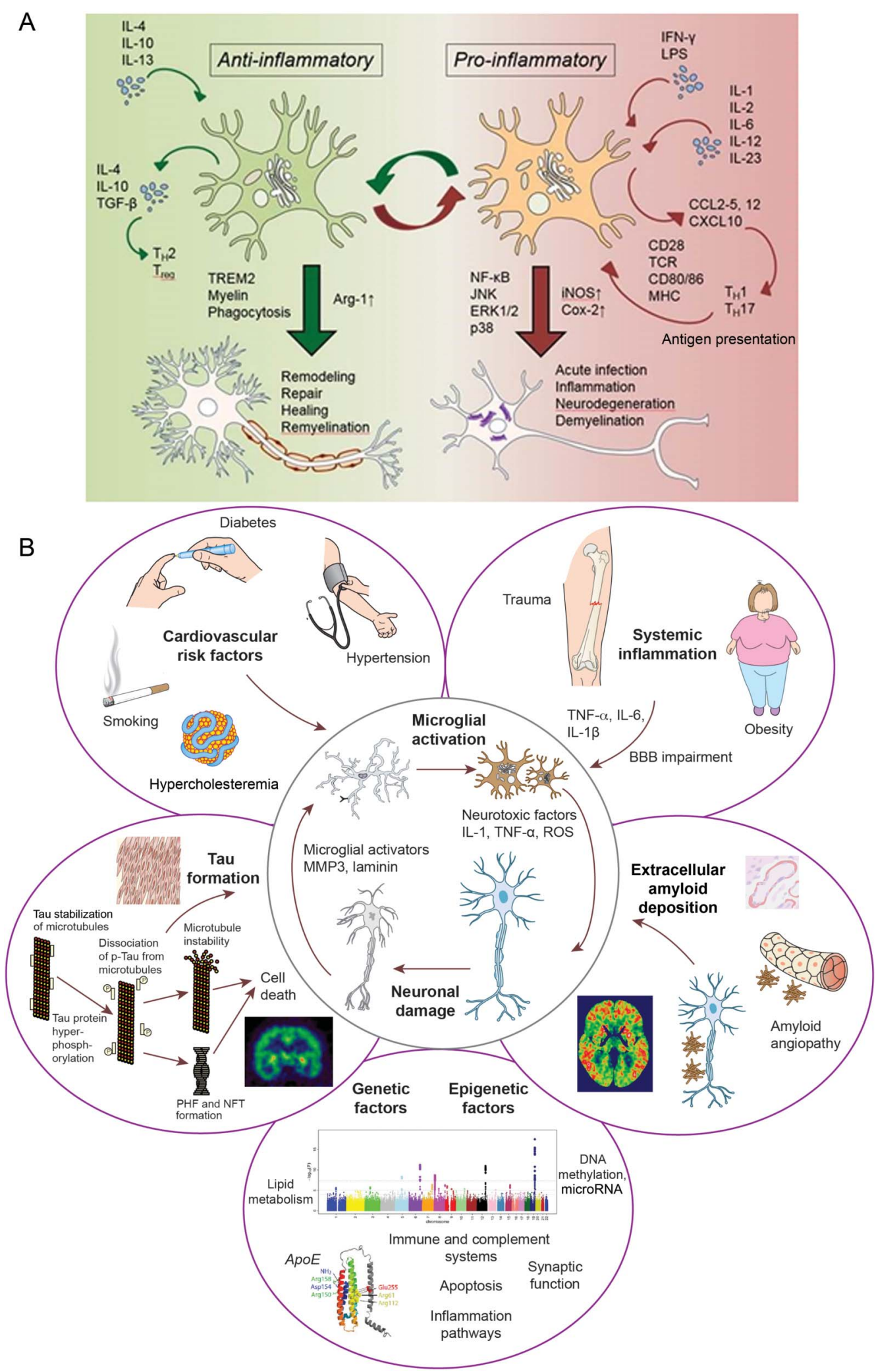

(A) Microglia can be activated by either anti-inflammatory stimuli (IL-4, IL-10, or IL-13) or proinflammatory cytokines (IFN-, LPS) that determine the polarization status of the cell. The anti- and proinflammatory responses involve the activation of different intracellular pathways and result in opposite effects on neuronal cells. (B) Systemic (cardiovascular risk factors and systemic inflammation), local (amyloid deposition and tangle formation), and genetic factors contribute to microglial activation. BBB = blood-brain barrier; COX-2 = cyclooxygenase-2; IFN = interferon; IL = interleukin; iNOS = inducible nitric oxide synthase; $\mathrm{LPS}$ = lipopolysaccharide; $\mathrm{MHC}=$ major histocompatibility complex; NF-KB = nuclear factor $\mathrm{KB} ; \mathrm{NFT}$ = neurofibrillary tangles; $\mathrm{PHF}=$ paired helical filaments; $\mathrm{p}$-tau = phosphorylated tau; ROS = reactive oxygen species; TCR = T cell receptor; TGF- $\beta=$ transforming growth factor $\beta$. 
Table 5 Clusters of voxel-wise correlation between $\left[{ }^{11} \mathrm{C}\right] \mathrm{PBR} 28 \mathrm{~V}_{\mathrm{T}}$ and hippocampal volume

\begin{tabular}{|c|c|c|c|c|c|c|}
\hline \multirow[b]{2}{*}{ Region } & \multirow[b]{2}{*}{ Size } & \multicolumn{3}{|c|}{ MNI coordinates } & \multirow[b]{2}{*}{$z$ Score } & \multirow[b]{2}{*}{ Corrected $p$ value } \\
\hline & & $x$ & $\mathbf{Y}$ & z & & \\
\hline \multicolumn{7}{|l|}{ HAB MCI cohort } \\
\hline Right inferolateral parietal lobe & & 48 & -24 & 36 & 6.55 & $<0.0001$ \\
\hline Right lateral occipital lobe & & 20 & -84 & 10 & 6.55 & \\
\hline Right superior frontal gyrus & & 4 & 49 & 5 & 6.55 & \\
\hline Right inferior frontal gyrus & & 42 & 19 & 18 & 6.55 & \\
\hline Right cuneus & 617,872 & 20 & -71 & 16 & 6.55 & \\
\hline Left superior temporal gyrus & & -39 & -32 & 7 & 6.55 & \\
\hline Left inferior frontal gyrus & & -59 & 15 & 12 & 6.55 & \\
\hline Right posterior temporal lobe & & 23 & -39 & 10 & 6.55 & \\
\hline Left posterior temporal lobe & & -49 & -37 & 4 & 6.55 & \\
\hline Right precentral gyrus & 844 & 18 & -16 & 55 & 7.01 & $<0.0001$ \\
\hline Right superior frontal gyrus & & 18 & -12 & 54 & 6.94 & \\
\hline Right postcentral gyrus & & 28 & -28 & 66 & 6.93 & \\
\hline Left superior frontal gyrus & 221 & -13 & 6 & 59 & 7.01 & $<0.0001$ \\
\hline Left precentral gyrus & & -24 & -22 & 62 & 6.90 & \\
\hline \multicolumn{7}{|l|}{ MAB MCI cohort } \\
\hline Left lateral occipital lobe & & -14 & -94 & -20 & 5.91 & $<0.0001$ \\
\hline Left thalamus & & -13 & -30 & 3 & 5.90 & \\
\hline Left posterior temporal lobe & 605,231 & -29 & -39 & -1 & 5.88 & \\
\hline Right posterior temporal lobe & & 26 & -33 & -2 & 5.88 & \\
\hline Left lingual gyrus & & -8 & -89 & -16 & 5.84 & \\
\hline Left fusiform gyrus & 332 & -33 & -5 & -46 & 5.09 & $<0.0001$ \\
\hline Left anterior temporal lobe & & -43 & 3 & -43 & 5.04 & \\
\hline
\end{tabular}

Abbreviations: $\mathrm{HAB}=$ high-affinity binder; $\mathrm{MAB}=$ mixed-affinity binder; $\mathrm{MCl}=$ mild cognitive impairment; $\mathrm{MNI}=$ Montreal Neurological Institute; $\mathrm{V}_{\mathrm{T}}=$ volume of distribution.

The table shows significant positive correlations between $\left[{ }^{11} \mathrm{C}\right] \mathrm{PBR} 28 \mathrm{~V}_{\mathrm{T}}$ and hippocampal volume in $\mathrm{HAB}$ and $\mathrm{MAB} \mathrm{MCl}$ cohorts using multiple regression analysis.

microglial activation go hand in hand in the early stages of the disease. Moreover, a recent trial of minocycline in patients with traumatic brain injury was able to show that while minocycline reduced chronic microglial activation, it also increased neurodegeneration, further suggesting that microglial activation might have a reparative effect. ${ }^{41}$

On an individual basis, we have been able to demonstrate that $35 \%$ of patients with $\mathrm{MCI}$ had significantly increased $\left[{ }^{11} \mathrm{C}\right]$ PBR28 binding compared to controls. Previously, it has been shown that significantly higher cortical $\left[{ }^{11} \mathrm{C}\right]$ PBR28 binding is present in patients with $\mathrm{AD}$ compared with controls, but conflicting results have been reported in MCI. ${ }^{42-47}$ The discrepancy in the findings between the studies may partly reflect the different methods used for the analysis, along with heterogeneity of the patients with MCI who were studied. In this study, we quantified regional cerebral $\left[{ }^{11} \mathrm{C}\right] \mathrm{PBR} 28 \mathrm{~V}_{\mathrm{T}}$ using a metabolite-corrected arterial input, while most other studies have normalized regional tracer activity to that of the cerebellum. However, the cerebellum may exhibit microglial activation in $\mathrm{AD}$ and, therefore, provides a suboptimal reference region. In addition, levels of microglial activation are likely to differ across different regions in different individuals and so averaging regional uptake and reporting a group mean in a heterogeneous disease may underestimate the true prevalence of microglial activation. However, limitations from the use of $\left[{ }^{11} \mathrm{C}\right] \mathrm{PBR} 28$ have to be acknowledged, and those might be responsible for the lack of group differences and the small number of "microglial-positive" patients. $\left[{ }^{11} \mathrm{C}\right] \mathrm{PBR} 28$ shows a high test-retest variability in healthy controls (approximately $15 \%$ ), and TSPO expression in the brain might be influenced by peripheral leucocyte counts. ${ }^{48,49}$ Moreover, free fraction of 
plasma tracer is another source of variability and the analytical method used might contribute to the lack of group difference. Our study population included both $\mathrm{MAB}$ and $\mathrm{HAB}$ and, as previously demonstrated by our group, the rs6971 singlenucleotide polymorphism of the TSPO gene, other than affecting $\left[{ }^{11} \mathrm{C}\right] \mathrm{PBR} 28$ and other second-generation TSPO tracers binding, does not affect any others of the clinical, neuropsychological, and biomarker characteristics of an $\mathrm{AD}$ or MCI population; thus, the results of the genetic subgroups can be applied to the entire MCI population. ${ }^{50}$

Contrary to conventional wisdom, demonstration of correlation with gray matter volume and hippocampal volume is of great significance to our knowledge about microglial activation and future therapeutic strategies to influence microglial activation. Hippocampal volume in $\mathrm{AD}$ correlates with cognitive performance, with higher hippocampal volume associated with better performance in cognitive function. Moreover, hippocampal atrophy is a predictor of progression to $\mathrm{AD}$ in individuals with $\mathrm{MCI} .{ }^{51}$ However, atrophy in the $\mathrm{AD}$ trajectory does not only affect the hippocampus, and several VBM studies have shown that MRI gray matter density is generally reduced in $\mathrm{AD} .^{52} \mathrm{~A}$ recent meta-analysis of VBM studies reports that gray matter atrophy in medial temporal lobe structures is a predictor of conversion in MCI. ${ }^{53}$ The pattern of atrophy in our amyloidpositive patients with $\mathrm{MCI}$ is consistent with the $\mathrm{AD}$ profile (reduced hippocampal and amygdala volumes and enlarged lateral ventricles) while amyloid-negative patients show preserved medial temporal lobe structures but enlarged ventricles compared to controls, which cannot be attributed to age. ${ }^{54,55}$

Recently, we have demonstrated that there are 2 peaks of microglial activation in the $\mathrm{AD}$ trajectory, ${ }^{25}$ and one could argue that the presence of microglial activation that is associated with preservation of brain volume could substantiate the presence of an early protective peak of microglial activation. ${ }^{56}$ If the hypothesis of differential activation of microglia is true, one could further hypothesize that agents promoting an anti-inflammatory phenotype of microglia may be beneficial in the early stages of the disease, while agents suppressing the proinflammatory phenotype may be beneficial in later stages of the disease, especially when dementia sets in. However, brain volume changes may not be solely driven by neuronal loss. Trials of active antiamyloid immunotherapy in $\mathrm{AD}$ have shown that treatment was able to induce reduction of gray matter volume, especially in responders, while improving cognition. It is hypothesized that volume loss in these patients could be attributable to reduction in interstitial or glial constituents, as well as removal of amyloid plaques. ${ }^{57,58}$ Therefore, preservation of brain volume associated with microglial activation in our study could not be simplistically attributed to neuronal cell numbers preservation.

While our findings suggest that microglial activation in the early phase of the disease is associated with higher hippocampal and gray matter volume and point toward a beneficial role, there is significant evidence to suggest that microglial activation in the later stage of the disease is associated with neuronal damage. ${ }^{59}$ It is very likely that microglial activation in different stages is associated with different functions, and as shown in data available from Dryad (supplemental figure 1B, doi.org/10.5061/dryad.6mp3r21), multiple factors could contribute to microglial activation, neuroinflammation, and neurodegeneration, with and without the presence of amyloid. These factors may very well be acting during the prodromal stages of the disease. An effective therapeutic strategy might require selective targeting of the different stages of microglial activation.

A limitation of this study is that we did not perform a partial volume correction for $\left[{ }^{11} \mathrm{C}\right] \mathrm{PBR} 28 \mathrm{PET}$, even though when defining ROIs, we used a probabilistic atlas that takes into account variations in individual brain structures. While this may have resulted in an underestimation of cortical $\mathrm{V}_{\mathrm{T}}$, it is likely that positive values will only be augmented with partial volume correction. Another limitation is the younger control group used in this study; however, studies have demonstrated that cortical microglial activation is minimally affected by normal aging in humans and its presence represents a diseasespecific process. $^{60}$ The study population is limited to 37 patients with $\mathrm{MCI}$, so the results of this pilot study will be strengthened by studies with larger populations and longitudinal series.

\section{Conclusion}

In this study, we report that $\left[{ }^{11} \mathrm{C}\right] \mathrm{PBR} 28 \mathrm{~V}_{\mathrm{T}}$ was associated with higher gray matter volume and higher hippocampal volume in patients with MCI. Based on the findings from this study, one could argue that microglial activation may not always be detrimental, and in the early stages of neurodegenerative diseases such as $\mathrm{AD}$, it may have a beneficial role in preserving brain volume. While further longitudinal studies are essential to evaluate the causal relationship, these findings from our pilot study have important implications in developing therapeutic strategies modulating microglial activation in $\mathrm{AD}$ and other diseases.

\section{Author contributions}

G.D. Femminella and M. Dani collected and analyzed the data and drafted the manuscript. M. Wood, V. Calsolaro, and R. Atkinson collected the data and revised the manuscript. G.D. Femminella and Z. Fan performed the statistical analysis. T. Edginton and R. Hinz critically reviewed the manuscript. D.J. Brooks and P. Edison designed the study, critically evaluated the study, and reviewed and revised the manuscript.

\section{Acknowledgment}

The authors thank the Imanova Centre for Imaging Sciences, Imperial College Clinical Imaging Facility, and GE Healthcare for the provision of radiotracers, scanning, and blood analysis equipment. The PET and MRI scans were funded by the 
Medical Research Council (MRC) and Alzheimer's Research UK. This report presents independent research funded by the MRC and Alzheimer's Research, UK, and is supported by the NIHR CRF and BRC at Imperial College Healthcare NHS Trust. The views expressed are those of the authors and not necessarily those of the MRC, the NHS, the NIHR, or the Department of Health.

\section{Study funding}

The PET scans and MRI scans were funded by the Medical Research Council (grant WMCN_P33428) and part of the study was funded by Alzheimer's Research UK (grant WMCN_P23750), while amyloid tracer was made available by GE Healthcare.

\section{Disclosure}

G. Femminella, M. Dani, M. Wood, Z. Fan, V. Calsolaro, R. Atkinson, T. Edginton, and R. Hinz report no disclosures relevant to the manuscript. D. Brooks has received research grants and nonfinancial support from the Medical Research Council, grants from Alzheimer's Research Trust, during the conduct of the study; other from GE Healthcare, personal fees from AstraZeneca, personal fees from Cytox, personal fees from Shire, personal fees from Novartis, personal fees from GSK, Holland, personal fees from Navidea, personal fees from UCB, personal fees from Acadia, grants from the Michael J. Fox Foundation, grants from the European Commission, outside the submitted work. P. Edison was funded by the Medical Research Council and now by Higher Education Funding Council for England (HEFCE). He has also received grants from Alzheimer's Research, UK, Alzheimer's Drug Discovery Foundation, Alzheimer's Society, UK, Novo Nordisk, GE Healthcare, AstraZeneca, Pfizer, Eli Lilly, and Piramal Life Sciences. Go to Neurology.org/N for full disclosures.

\section{Publication history}

Received by Neurology April 10, 2018. Accepted in final form November 14, 2018.

\section{References}

1. Asih PR, Chatterjee P, Verdile G, Gupta VB, Trengove RD, Martins RN. Clearing the amyloid in Alzheimer's: progress towards earlier diagnosis and effective treatments: an update for clinicians. Neurodegener Dis Manag 2014;4:363-378.

2. Heneka MT, Carson MJ, El Khoury J, et al. Neuroinflammation in Alzheimer's disease. Lancet Neurol 2015;14:388-405.

3. Keren-Shaul H, Spinrad A, Weiner A, et al. A unique microglia type associated with restricting development of Alzheimer's disease. Cell 2017;169:1276-1290.e17.

4. Kreisl WC. Discerning the relationship between microglial activation and Alzheimer's disease. Brain 2017;140:1825-1828.

5. Hansen DV, Hanson JE, Sheng M. Microglia in Alzheimer's disease. J Cell Biol 2018; 217:459-472.

6. Spangenberg EE, Green KN. Inflammation in Alzheimer's disease: lessons learned from microglia-depletion models. Brain Behav Immun 2017;61:1-11.

7. Castillo E, Leon J, Mazzei G, et al. Comparative profiling of cortical gene expression in Alzheimer's disease patients and mouse models demonstrates a link between amyloidosis and neuroinflammation. Sci Rep 2017;7:17762.

8. Tichauer JE, von Bernhardi R. Transforming growth factor-beta stimulates beta amyloid uptake by microglia through Smad3-dependent mechanisms. J Neurosci Res 2012;90:1970-1980.

9. Wyss-Coray T, Lin C, Yan F, et al. TGF-betal promotes microglial amyloid-beta clearance and reduces plaque burden in transgenic mice. Nat Med 2001;7:612-618.

10. Varley J, Brooks DJ, Edison P. Imaging neuroinflammation in Alzheimer's disease and other dementias: recent advances and future directions. Alzheimers Dement 2015;11:1110-1120.

11. Imaizumi M, Kim HJ, Zoghbi SS, et al. PET imaging with [11C]PBR28 can localize and quantify upregulated peripheral benzodiazepine receptors associated with cerebral ischemia in rat. Neurosci Lett 2007;411:200-205.
12. Okello A, Edison P, Archer HA, et al. Microglial activation and amyloid deposition in mild cognitive impairment: a PET study. Neurology 2009;72:56-62.

13. Kreisl WC, Fujita M, Fujimura Y, et al. Comparison of [(11)C]-(R)-PK 11195 and [(11)C]PBR28, two radioligands for translocator protein $(18 \mathrm{kDa})$ in human and monkey: implications for positron emission tomographic imaging of this inflammation biomarker. Neuroimage 2010;49:2924-2932.

14. Mirzaei N, Tang SP, Ashworth S, et al. In vivo imaging of microglial activation by positron emission tomography with $\left[{ }^{11} \mathrm{C}\right] \mathrm{PBR} 28$ in the 5XFAD model of Alzheimer's disease. Glia 2016;64:993-1006.

15. Mechelli A, Price CJ, Friston KJ, Ashburner J. Voxel-based morphometry of the human brain: methods and applications. Curr Med Imaging Rev 2005;1:105-113.

16. Petersen RC. Mild cognitive impairment as a diagnostic entity. J Intern Med 2004; 256:183-194.

17. Albert MS, DeKosky ST, Dickson D, et al. The diagnosis of mild cognitive impairment due to Alzheimer's disease: recommendations from the National Institute on Aging-Alzheimer's Association Workgroups on Diagnostic Guidelines for Alzheimer's Disease. Alzheimers Dement 2011;7:270-279.

18. Owen DR, Yeo AJ, Gunn RN, et al. An 18-kDa translocator protein (TSPO) polymorphism explains differences in binding affinity of the PET radioligand PBR28. J Cereb Blood Flow Metab 2012;32:1-5.

19. Datta G, Colasanti A, Kalk N, et al. (11)C-PBR28 and (18)F-PBR111 detect white matter inflammatory heterogeneity in multiple sclerosis. J Nucl Med 2017;58: $1477-1482$.

20. Fan Z, Dani M, Femminella GD, et al. Parametric mapping using spectral analysis for 11C-PBR28 PET reveals neuroinflammation in mild cognitive impairment subjects. Eur J Nucl Med Mol Imaging 2018;45:1432-1441.

21. Hammers A, Chen $\mathrm{CH}$, Lemieux L, et al. Statistical neuroanatomy of the human inferior frontal gyrus and probabilistic atlas in a standard stereotaxic space. Hum Brain Mapp 2007;28:34-48.

22. Chételat G, Desgranges B, Landeau B, et al. Direct voxel-based comparison between grey matter hypometabolism and atrophy in Alzheimer's disease. Brain 2008;131: $60-71$.

23. Edison P, Rowe CC, Rinne JO, et al. Amyloid load in Parkinson's disease dementia and Lewy body dementia measured with [11C]PIB positron emission tomography. J Neurol Neurosurg Psychiatry 2008;79:1331-1338.

24. Edison P, Ahmed I, Fan Z, et al. Microglia, amyloid, and glucose metabolism in Parkinson's disease with and without dementia. Neuropsychopharmacology 2013;38: 938-949.

25. Fan Z, Brooks DJ, Okello A, Edison P. An early and late peak in microglial activation in Alzheimer's disease trajectory. Brain 2017;140:792-803.

26. Fan Z, Aman Y, Ahmed I, et al. Influence of microglial activation on neuronal function in Alzheimer's and Parkinson's disease dementia. Alzheimers Dement 2015;11: 608-621.e7.

27. Casanova R, Srikanth R, Baer A, et al. Biological parametric mapping: a statistical toolbox for multimodality brain image analysis. Neuroimage 2007;34:137-143.

28. Dani M, Wood M, Mizoguchi R, et al. Microglial activation correlates in vivo with both tau and amyloid in Alzheimer's disease. Brain 2018;141:2740-2754.

29. Hannestad J, Gallezot JD, Schafbauer T, et al. Endotoxin-induced systemic inflammation activates microglia: $\left[{ }^{11} \mathrm{C}\right] \mathrm{PBR} 28$ positron emission tomography in nonhuman primates. Neuroimage 2012;63:232-239.

30. Hamelin L, Lagarde J, Dorothée G, et al. Early and protective microglial activation in Alzheimer's disease: a prospective study using 18F-DPA-714 PET imaging. Brain 2016;139:1252-1264.

31. Jack CR Jr, Bennett DA, Blennow K, et al. NIA-AA Research Framework: toward a biological definition of Alzheimer's disease. Alzheimers Dement 2018;14:535-562.

32. Jack CR Jr, Knopman DS, Chetelat G, et al. Suspected non-Alzheimer disease pathophysiology: concept and controversy. Nat Rev Neurol 2016;12:117-124.

33. Fan Z, Okello AA, Brooks DJ, Edison P. Longitudinal influence of microglial activation and amyloid on neuronal function in Alzheimer's disease. Brain 2015;138: 3685-3698.

34. Femminella GD, Ninan S, Atkinson R, Fan Z, Brooks DJ, Edison P. Does microglial activation influence hippocampal volume and neuronal function in Alzheimer's disease and Parkinson's disease dementia? J Alzheimers Dis 2016;51:1275-1289.

35. Parbo P, Ismail R, Hansen KV, et al. Brain inflammation accompanies amyloid in the majority of mild cognitive impairment cases due to Alzheimer's disease. Brain 2017; 140:2002-2011.

36. Lyman M, Lloyd DG, Ji X, Vizcaychipi MP, Ma D. Neuroinflammation: the role and consequences. Neurosci Res 2014;79:1-12.

37. Jimenez S, Baglietto-Vargas D, Caballero C. Inflammatory response in the hippocampus of PS1M146L/APP751SL mouse model of Alzheimer's disease: Agedependent switch in the microglial phenotype from alternative to classic. J Neurosci. 2008;28:11650-61.

38. Varnum MM, Ikezu T. The classification of microglial activation phenotypes on neurodegeneration and regeneration in Alzheimer's disease brain. Arch Immunol Ther Exp 2012;60:251-266.

39. Schöll M, Carter SF, Westman E, et al. Early astrocytosis in autosomal dominant Alzheimer's disease measured in vivo by multi-tracer positron emission tomography. Sci Rep 2015;5:16404.

40. Rodriguez-Vieitez E, Saint-Aubert L, Carter SF, et al. Diverging longitudinal changes in astrocytosis and amyloid PET in autosomal dominant Alzheimer's disease. Brain 2016;139:922-936.

41. Scott G, Zetterberg H, Jolly A, et al. Minocycline reduces chronic microglial activation after brain trauma but increases neurodegeneration. Brain 2018;141:459-471. 
42. Kropholler MA, Boellaard R, van Berckel BN, et al. Evaluation of reference regions for (R)-[(11)C]PK11195 studies in Alzheimer's disease and mild cognitive impairment. J Cereb Blood Flow Metab 2007;27:1965-1974.

43. Yaqub M, van Berckel BN, Schuitemaker A, et al. Optimization of supervised cluster analysis for extracting reference tissue input curves in (R)-[(11)C]PK11195 brain PET studies. J Cereb Blood Flow Metab 2012;32:1600-1608.

44. Schuitemaker A, Kropholler MA, Boellaard R, et al. Microglial activation in Alzheimer's disease: an (R)-[(11)C]PK11195 positron emission tomography study. Neurobiol Aging 2013;34:128-136.

45. Kreisl WC, Lyoo $\mathrm{CH}, \mathrm{McGwier} \mathrm{M}$, et al. In vivo radioligand binding to translocator protein correlates with severity of Alzheimer's disease. Brain 2013;136: 2228-2238.

46. Yasuno F, Kosaka J, Ota M, et al. Increased binding of peripheral benzodiazepine receptor in mild cognitive impairment-dementia converters measured by positron emission tomography with $\left[{ }^{11} \mathrm{C}\right] \mathrm{DAA} 1106$. Psychiatry Res 2012;203:67-74.

47. Knezevic D, Verhoeff NPL, Hafizi S, et al. Imaging microglial activation and amyloid burden in amnestic mild cognitive impairment. J Cereb Blood Flow Metab 2018;38: 1885-1895.

48. Collste K, Forsberg A, Varrone A, et al. Test-retest reproducibility of [(11)C $]$ PBR28 binding to TSPO in healthy control subjects. Eur J Nucl Med Mol Imaging 2016;43: 173-183.

49. Kanegawa N, Collste K, Forsberg A, et al. In vivo evidence of a functional association between immune cells in blood and brain in healthy human subjects. Brain Behav Immun 2016;54:149-157.

50. Fan Z, Harold D, Pasqualetti G, Williams J, Brooks DJ, Edison P. Can studies of neuroinflammation in a TSPO genetic subgroup (HAB or MAB) be applied to the entire AD cohort? J Nucl Med 2015;56:707-713.
51. Ries ML, Carlsson CM, Rowley HA, et al. Magnetic resonance imaging characterization of brain structure and function in mild cognitive impairment: a review. J Am Geriatr Soc 2008;56:920-934.

52. Karas GB, Scheltens P, Rombouts SA, et al. Global and local gray matter loss in mild cognitive impairment and Alzheimer's disease. Neuroimage 2004;23:708-716.

53. Ferreira LK, Diniz BS, Forlenza OV, Busatto GF, Zanetti MV. Neurostructural predictors of Alzheimer's disease: a meta-analysis of VBM studies. Neurobiol Aging 2011; 32:1733-1741.

54. Spulber G, Simmons A, Muehlboeck JS, et al. An MRI-based index to measure the severity of Alzheimer's disease-like structural pattern in subjects with mild cognitive impairment. J Intern Med 2013;273:396-409.

55. Apostolova LG, Green AE, Babakchanian S, et al. Hippocampal atrophy and ventricular enlargement in normal aging, mild cognitive impairment (MCI), and Alzheimer disease. Alzheimer Dis Assoc Disord 2012;26:17-27.

56. Lopez-Picon FR, Snellman A, Eskola O, et al. Neuroinflammation appears early and then plateaus in a mouse model of Alzheimer's disease shown by PET imaging. J Nucl Med 2018;59:509-515.

57. Vandenberghe R, Riviere ME, Caputo A, et al. Active Abeta immunotherapy CAD106 in Alzheimer's disease: a phase 2b study. Alzheimers Dement 2017;3:10-22.

58. Fox NC, Black RS, Gilman S, et al. Effects of Abeta immunization (AN1792) on MRI measures of cerebral volume in Alzheimer disease. Neurology 2005;64:1563-1572.

59. Hopperton KE, Mohammad D, Trépanier MO, Giuliano V, Bazinet RP. Markers of microglia in post-mortem brain samples from patients with Alzheimer's disease: a systematic review. Mol Psychiatry 2018;23:177-198.

60. Suridjan I, Rusjan PM, Voineskos AN, et al. Neuroinflammation in healthy aging: a PET study using a novel translocator protein $18 \mathrm{kDa}(\mathrm{TSPO})$ radioligand, [(18)F]FEPPA. Neuroimage 2014;84:868-875. 


\section{Neurology}

\section{Microglial activation in early Alzheimer trajectory is associated with higher gray matter volume \\ Grazia Daniela Femminella, Melanie Dani, Melanie Wood, et al. \\ Neurology 2019;92;e1331-e1343 Published Online before print February 22, 2019 \\ DOI 10.1212/WNL.0000000000007133}

This information is current as of February 22, 2019

\section{Updated Information \&} Services

References

Citations

Subspecialty Collections

Permissions \& Licensing

Reprints including high resolution figures, can be found at: http://n.neurology.org/content/92/12/e1331.full

This article cites 60 articles, 8 of which you can access for free at: http://n.neurology.org/content/92/12/e1331.full\#ref-list-1

This article has been cited by 1 HighWire-hosted articles: http://n.neurology.org/content/92/12/e1331.full\#\#otherarticles

This article, along with others on similar topics, appears in the following collection(s):

Alzheimer's disease

http://n.neurology.org/cgi/collection/alzheimers_disease

MCI (mild cognitive impairment)

http://n.neurology.org/cgi/collection/mci_mild_cognitive_impairment

MRI

http://n.neurology.org/cgi/collection/mri

PET

http://n.neurology.org/cgi/collection/pet

Information about reproducing this article in parts (figures,tables) or in its entirety can be found online at:

http://www.neurology.org/about/about_the_journal\#permissions

Information about ordering reprints can be found online:

http://n.neurology.org/subscribers/advertise

Neurology ${ }^{\circledR}$ is the official journal of the American Academy of Neurology. Published continuously since 1951, it is now a weekly with 48 issues per year. Copyright Copyright ( 2019 The Author(s). Published by Wolters Kluwer Health, Inc. on behalf of the American Academy of Neurology.. All rights reserved. Print ISSN: 0028-3878. Online ISSN: 1526-632X.

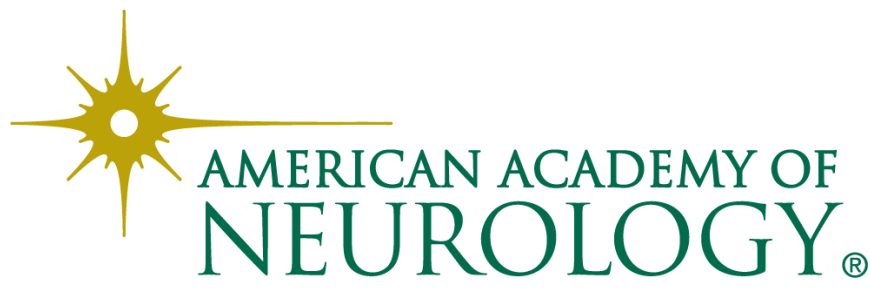

